\title{
Comparison of Effects Endurance and Resistance Exercise on Static and Dynamic Balance in Obese Adolescent Boys
}

\author{
Agustina Mufidah, Sri Mardjiati Mei Wulan*, Nurul Kusuma Wardani
}

\author{
*Email: meiwulan21@gmail.com \\ Department of Physical Medicine and Rehabilitation, Faculty of Medicine, Universitas Airlangga/Dr. Soetomo \\ Academic General Hospital Surabaya Indonesia
}

\begin{abstract}
The pathological condition of obesity has an effect on quality of life. The larger body size, the greater body mass index, the abnormal body fat distribution, and the potential for neuromuscular disorders in obese children contribute to their body instability, resulting in poor static and dynamic stability. Poor body stability in obese adolescents can lead to a higher risk of falls and fractures. Daily physical activities and exercise are the main solutions to deal with balance problems in obese individuals. The exercise intervention that is often recommended for obese children and adolescents is endurance training, but the level of compliance is low because it takes a long time. Resistance training is an alternative that can be given but requires supervision to avoid the risk of injury. The purpose of this study was to compare of effects endurance and resistance training on static and dynamic balance in obese adolescent boys. This study was conducted from July 2020 to September 2020. The subjects were adolescent boys aged 14-18 years with an age-appropriate body mass index (CDC BMI chart 2000) > P95. Twenty-five subjects were randomized into two groups, endurance and resistance groups. Frequency resistance training 3 times a week for 8 weeks. The intensity was determined using the Borg scale, increasing gradually. Endurance training starts with light intensity and increasing gradually to moderate intensity with aerobic exercise (Zumba fitness) for 30-60 minutes, a frequency of 3 times a week for 8 weeks. This study was conducted without calorie restriction. The assessments include static balance with the Standing Stork test and dynamic balance with the Modified BASS Balance test. The pre - intervention static balance in endurance group was $2.21 \pm 0.80$, and post-intervention $3.93 \pm 1.44$, significance 0.002 , while the pre-intervention in resistance group was $2.30 \pm 0.67$ and post-intervention was $4.05 \pm 1.66$ the significance 0.001 . The dynamic balance data for the pre-intervention endurance group was $79.08 \pm 11.1$ and post-intervention $94.17 \pm 6.29$, with significance 0.000 , while the pre-intervention in resistance group was $75.85 \pm 14.88$ and post-intervention was $95.38 \pm 6.29$, with significance 0.000 . The changes in static and dynamic balance before and after intervention between the 2 groups there was no significant difference with p-value of 0.955 for static balance and p-value of 0.288 for dynamic balance. Endurance training and resistance training regularly 3 times a week for 8 weeks have an effect on improving static and dynamic balance in obese adolescent boys.
\end{abstract}

Keywords: Endurance training, zumba fitness, resistance training, balance, obesity, Indonesia

\section{INTRODUCTION}

Obesity among adolescents has short-term and long-term consequences in terms of physical and psychosocial development (Elissa and Whitney, 2016). The prevalence of overweight and obesity in children and adolescents in the world increased from $4.2 \%$ in 1990 to $6.7 \%$ in 2010, and is expected to reach $9.1 \%$ in 2020 (Madarina, 2014; Damayanti et al, 2014) . More than 10\% of children and adolescents in big cities in Indonesia are obese, based on data from the 2013 Basic Health Research (Riskesdas) the prevalence of obesity based on weight/height in children under five in 2007, 2010 and 2013 respectively $12,2 \%, 14.0 \%$, and $11.9 \%$, respectively. as well as children/adolescents aged 5-12,13-15, and 16-18 years old based on body mass index were $8.8 \%, 2.5 \%$, respectively. and 1.6\% (Madarina, 2014 and Damayanti et al, 2014).

The pathological condition of obesity has a profound effect on disability and quality of life. Larger body size, greater body mass index, abnormal body fat distribution, and the potential for neuromuscular disorders in obese adolescents contribute to their posture instability, resulting in poor static and dynamic postural stability (Fenghua Sun et al, 2015). Poor posture stability in obese adolescents can lead to a higher risk of falls and fractures compared to normal weight adolescents (Lucky et al, 2017; Capodaglio et al, 2012).

There are differences in body fat patterns between men and women, this is influenced by hormones. In men affected by the android hormone, relatively large fat accumulates in the upper body, while in women it is influenced by the gynoid hormone, relatively large body fat in the hip and thigh area. The distribution of body fat is partly controlled by hormones, and this is especially important at puberty. In a study stated that gender plays a role in influencing balance, this is due to the distribution of fat and the level of muscle mass in the body. Men have less fat and more muscle mass than women who have more subcutaneous fat. The male hormone testosterone affects the synthesis of proteins that are useful for the formation of muscle mass, and muscle mass is needed for muscle strength. The female hormone estrogen regulates fat distribution, where more fat deposits in the muscles (Helen, 2008; Michael, 2010) 
Weight loss in obese adolescents is associated with a decrease in body mass index and body fat, an increase in physical activity, and an increase in movement skills. One study found that weight loss in obese adults improved their posture stability. However, only a few studies have examined the effect of body weight on reducing postural balance in obese children and adolescents (Fenghua Sun et al, 2015).

Daily physical activities and exercise can be the main solution to deal with balance problems in adolescents with obesity. A study found that weight loss in obese adolescents could improve their posture stability. Endurance training or also known as aerobic exercise is an exercise with a fairly long period of time with low to moderate intensity and uses aerobic metabolism, but the most common limitation is adherence to this type of exercise. Resistance training has long been prohibited for use in children and adolescents because it is considered a risk of causing musculoskeletal injury or having a negative effect because of the effect of mechanical constraints. In the case of obese, resistance training is not recommended because it produces low energy expenditure and has minimal effect on adipocytes, but several recent studies have shown that resistance training in adolescents can be done safely and provides benefits if done with supervision and according to procedures (Aucouturier and Thivel , 2015).

Research on the comparison of the effects of endurance and resistance training on obese adolescent boys is still very limited. The purpose of this study was to compare the effects of endurance and resistance training on static and dynamic balance in obese adolescent boys.

\section{METODE}

The research method used is experimental with pre and post randomized group design. The subjects of this study were obese adolescent boys aged 14-18 years. Subjects who met the inclusion criteria and did not include the exclusion criteria were randomly divided into two groups, namely the endurance group and the resistance group. The technique of taking research subjects with consecutive sampling was then randomized using a lottery until the required number of subjects was reached. The research was conducted at 2 senior high school in Surabaya Indonesia from July to September 2020.

The sample size in the study was determined based on the formula (Lwanga \& Lemeshow, 2003):

$$
\begin{aligned}
& \mathrm{n}=2(\mathrm{Z} 1 / 2 \alpha+\mathrm{Z} \beta)^{2} \cdot \sigma^{2}=2(2.89)^{2}(1.96+1.28)^{2}=11 \\
& \left(\mu_{1}-\mu_{2}\right)^{2} \\
& \mathrm{n}=\text { number of subjects in each group. } \\
& \mathrm{Z} 1 / 2 \alpha=\text { alpha standard deviation }(\alpha=0.05)=1.96 \\
& \mathrm{Z} \beta=\text { Beta standard deviation }(\beta=0.10)=1.28
\end{aligned}
$$

Anticipation of dropping out of the $20 \%$ test is $2.2, n=11+2.2=13.2=14$ people. The number of research subjects for each group was 11 men. The total minimum number of research subjects is 22 people.

Inclusion criteria

- $\quad$ Male aged 14-18 years old,

- $\quad$ Body mass index according to age percentile (CDC BMI chart 2000) > P95.

- Subjects are willing to participate in this study by signing the informed consent form. And the subject's parents agreed to the subject's involvement by signing the consent form as a witness

Exclusion criteria

- Subjects are undergoing a routine aerobic or resistance training program (at least $2 x /$ week) and programmed in the last 2 months.

- Have a history of ischemic heart disease, heart failure. Have a history of asthma triggered by physical activity.

- Having comorbidities that require the subject to take medication regularly and affect body composition such as Cushing's syndrome, DM, hypothyroidism. Have a neuromusculoskeletal disease. Impaired vision and hearing that can interfere with audiovisual communication.

Dropout criteria

- Research subjects are not willing to continue the study for any reason.

- could not complete the exercise in accordance with the established research protocol, namely not following the program for 3 consecutive training sessions from the number of training sessions for 8 weeks.

- Subjects experienced complications during the exercise program such as shortness of breath, syncope, chest pain and other complications that made it impossible to continue the exercise.

Data analysis

The data were analyzed computerized with SPSS v20.o using several tests:

- Saphiro Wilk test to determine the normality of the data in each group of endurance and resistance training.

- Free sample $\mathrm{t}-2$ test (independent $\mathrm{t}$ test) to compare the initial characteristics of research subjects in the endurance and resistance groups before the exercise program if normally distributed. 
- Mann Whitney test to compare the initial characteristics of research subjects in the endurance and resistance groups before the exercise program if the distribution is not normal.

- Paired t-test to compare dynamic balance before and after an 8-week training program in the endurance and resistance training groups.

- Wilcoxon signed rank test to compare static balance before and after an 8-week training program in the endurance and resistance training groups.

- Independent $\mathrm{t}-2$ test (independent $\mathrm{t}$-test) to compare changes in static and dynamic balance before and after an 8-week training program in the endurance training group compared to resistance training.

The intervention carried out was endurance and resistance training without calorie restriction. Resistance exercises using body weights in the trunk, lower and upper extremity muscle groups with repetitions increasing gradually up to $15 \mathrm{x}$ for 4 sets (resting between sets of 2-3 minutes), frequency 3 times a week for 8 weeks. The intensity is determined using the Borg scale which can perform up to $5 \mathrm{x}$ on a scale of $14-15$ (90\% heavy intensity $1 \mathrm{RM}$ ), up to $10 \mathrm{x}$ on a $12-13$ scale (moderate $70 \% 1 \mathrm{RM}$ ), up to $15 \mathrm{x}$ on a $10-11$ scale (mild $50 \% 1 \mathrm{RM}$ ). The exercise is preceded by stretching for 8 repetitions for the head, neck, upper extremities, trunk, and lower extremities. The exercises include the following techniques: Jumping Jacks, Wall Sits, Push Up, Abdominal Crunch, Step-up on to chair, Squat, Tricep dip on chair, Plank, High Knees, Lunge, Push up and rotation, partial curl. Endurance training begins with light intensity (THR: 57-64\% HRMax) gradually increased to moderate intensity (THR: 64-76 HRMax) with aerobic exercise (zumba fitness) for 30-60 minutes, gradually increasing (preceded by a 5-10 minute warm-up, core 20-40 minutes, cool down 5-10 minutes), frequency 3 times a week for 8 weeks. The calculation of HRMax with the Astrand formula is HRMax $=216.6-(0.84 \mathrm{x}$ age $)$. Exercise includes whole body movement with a combination of aerobics and dance. The volume of exercise is increased gradually, starting with increasing duration and then increasing in intensity.

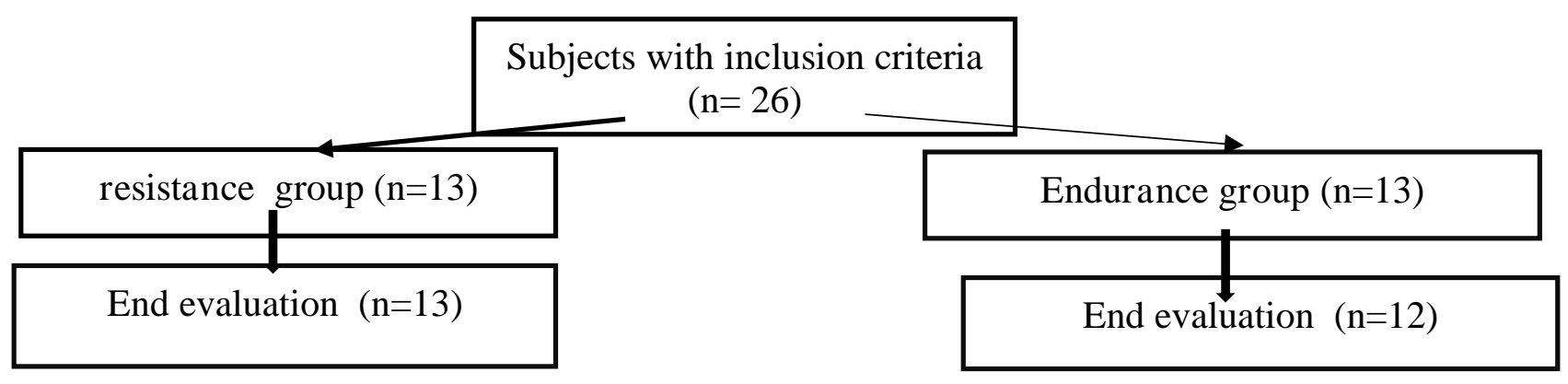

Figure 1. Research subject

Parameters evaluated in this study include BMI (body mass index), abdominal circumference, LBM (Lean Body Mass), static balance (KS) with standing Stork test and dynamic balance (KD) with modified BASS balance test. Assessment of all parameters was carried out twice, pre and post research. The total subjects of this study were 26 obese adolescent boys who were divided into 2 groups (endurance and resistance) with a random system. There was 1 person dropped out of the endurance group because the training schedule clashed with school activities.

\section{RESULT}

This research received ethical approval from the Health Research Ethics Committee, Faculty of Medicine, Airlangga University, Surabaya with No.120/EC/KEPK/FKUA/2020.

\section{Characteristics of Research Subjects for Endurance and Resistance Groups}

The subjects analyzed in this study were 25 adolescent boys diagnosed with obesity according to the 2000 $\mathrm{CDC}$ scheme, the research subjects were divided into 2 groups, resistance group of 13 peoples and endurance group of 12 peoples. The results of the homogeneity test using the Independent $t$ test (table 1) showed that the variables of body mass index (BMI), abdominal circumference, and dynamic balance in the endurance and resistance groups had no significant differences with $\mathrm{p}$ value $>0.05$. Mann Whitney test for variables of age, LBM, and static balance (KS) showed no significant difference in the two groups of endurance and resistance with p-value $>0.05$.

The data normality test used the Saphiro Wilk Test (table 2), the distribution of the data showed a normal distribution on the variables of body mass index (BMI), abdominal circumference, and dynamic balance (KD) in both groups, and LBM in the resistance group with $\mathrm{p}$ value $>0.05$, so used parametric statistical test. The variables 
of age, and static balance between the two groups, and LBM in the endurance group were not normally distributed (p-value <0.05) so the Mann Whitney non-parametric test was used.

Table 1 Initial characteristics of research subjects in the endurance and resistance groups

\begin{tabular}{|cccc|}
\hline variable & Endurance & Resistance & p-value \\
\hline BMI $\left(\mathrm{kg} / \mathrm{m}^{2}\right)$ & $32,75 \pm 3,77$ & $34,37 \pm 4,68$ & 0,361 \\
Age (years) & $15,50 \pm 0,52$ & $15,46 \pm 0,52$ & 0,851 \\
Abdominal circumference $(\mathrm{cm})$ & $105,79 \pm 7,38$ & $105,31 \pm 12,63$ & 0,900 \\
LBM (\%) & $61.43 \pm 5.36$ & $58.27 \pm 9.96$ & 0.301 \\
KS (s) & $2,21 \pm 0,80$ & $2,30 \pm 0,67$ & 0,429 \\
KD(score) & $79,08 \pm 11,1$ & $75,85 \pm 14,88$ & 0,547 \\
\hline
\end{tabular}

*Test for homogeneity with independent $t$ test and Mann Whitney is significant if $p$-value $<0.05$

Table 2 Test for normality of the characteristics of research subjects in the endurance and resistance group (preintervention)

\begin{tabular}{|ccccc|} 
Variable & Endurance Group & \multicolumn{2}{c|}{ Resistance Group } \\
& Mean & p-value & Mean & p-value \\
\hline BMI $\left(\mathrm{kg} / \mathrm{m}^{2}\right)$ & $32,75 \pm 3,77$ & $0,839^{*}$ & $34,37 \pm 4,68$ & $0,533^{*}$ \\
Age (years) & $15,50 \pm 0,52$ & 0,001 & $15,46 \pm 0,52$ & 0,001 \\
Abdomen Circumferance (cm) & $105,79 \pm 7,38$ & $0,160^{*}$ & $105,31 \pm 12,63$ & $0,220^{*}$ \\
LBM (\%) & $61.43 \pm 5.36$ & 0.001 & $58.27 \pm 9.96$ & $0.561^{*}$ \\
KS (s) & $2,21 \pm 0,80$ & 0,002 & $2,30 \pm 0,67$ & 0,034 \\
KD(score) & $79,08 \pm 11,1$ & $0,749^{*}$ & $75,85 \pm 14,88$ & $0,340^{*}$ \\
\hline
\end{tabular}

*Saphiro Wilk test is normally distributed if p-value $>0.05$

The results of the Saphiro Wilk test (table 2) show that the body mass index (BMI) data in the endurance and resistance groups are normally distributed, so parametric statistical tests are used. The body mass index of the pre-exercise endurance group averaged $32.75 \pm 3.77 \mathrm{~kg} / \mathrm{m} 2$ with a p-value of 0.839 , while the pre-exercise BMI resistance group averaged $34.37 \pm 4.68 \mathrm{~kg} / \mathrm{m} 2$ with a p-value of 0.533 . Based on the statistical test of the independent samples t test (table 1), there was no significant difference for the BMI of the research subjects between the two groups with a p-value of 0.361 .

The results of the Saphiro Wilk test (table 2) show that the age data in the endurance and resistance groups are not normally distributed, so non-parametric statistical tests are used. The average age of the endurance group was $15.50 \pm 0.52$ years with a p-value of 0.001 . The mean age of the research subjects from the resistance group was $15.46 \pm 0.52$ with a p-value of 0.001 . Based on the Mann Whitney statistical test (table 1), there was no significant difference for the age of the research subjects between the two groups with a p-value of 0.851 .

The results of the Saphiro Wilk test (table 2) show that the abdominal circumference data in the endurance and resistance groups were normally distributed, so parametric statistical tests were used. The abdominal circumference of the pre-exercise endurance group averaged $105.79 \pm 7.38 \mathrm{~cm}$ with a p-value of 0.160 , while the pre-exercise abdominal circumference resistance group averaged $105.31 \pm 12.63 \mathrm{~cm}$ with a p-value of 0.220. Based on the statistical test of the independent samples t test (table 1), there was no significant difference for the abdominal circumference of the research subjects between the two groups with a p-value of 0.900 .

The results of the Saphiro Wilk test (table 2) show that the LBM data in the endurance group is normally distributed and the resistance group is normally distributed, so parametric statistical tests are used. The lean body mass of the pre-exercise endurance group averaged $61.43 \pm 5.36 \%$ with a p-value of 0.001 , while the pre-exercise LBM resistance group averaged $58.27 \pm 9.96 \%$ with a p-value of 0.561 . Based on the Mann Whitney statistical test (table 1), there was no significant difference for the LBM of the research subjects between the two groups with a p-value of 0.301 .

The results of the Saphiro Wilk test (table 2) show that the KS data in the endurance and resistance groups are not normally distributed, so non-parametric statistical tests are used. The static balance of the preexercise endurance group averaged $2.21 \pm 0.80$ seconds with a p-value of 0.002 . In the resistance group, the average pre-exercise KS was $2.30 \pm 0.67$ seconds with a p-value of 0.34 . Based on the Mann Whitney statistical test (table 1), there was no significant difference for the KS of the research subjects between the two groups with a p-value of 0.429 .

The results of the Saphiro Wilk test (table 2) show that the KD data in the endurance and resistance groups are normally distributed, so parametric statistical tests are used. The dynamic balance of the pre-exercise endurance group averaged $79.08 \pm 11.1$ with a p-value of 0.749 . In the resistance group, the average pre-exercise KD was $75.85 \pm 14.88$ with a p-value of 0.340 . Based on the statistical test of the independent samples t test (table 
5.1), there was no significant difference for the KD of the research subjects between the two groups with a p-value of 0.547 .

Table 3. BMI data before and after Endurance and Resistance training

\begin{tabular}{|cccc|} 
Variable BMI & pre exercise $(\mathbf{n}=\mathbf{1 2})$ & $\begin{array}{c}\text { post Exercise } \\
(\mathbf{n}=\mathbf{1 2})\end{array}$ & $\begin{array}{c}\text { significance* } \\
\end{array}$ \\
\hline Endurance $\left(\mathrm{kg} / \mathrm{m}^{2}\right)$ & $32,75 \pm 3,77$ & $31,83 \pm 3,86$ & $0,001^{*}$ \\
Resistance $\left(\mathrm{kg} / \mathrm{m}^{2}\right)$ & $34,37 \pm 4,68$ & $34,07 \pm 5,02$ & 0,265 \\
\hline
\end{tabular}

*Test paired t test, the difference is significant if the value of significance $<0.05$

Table 4. Abdominal circumference before and after Endurance and Resistance exercise.

\begin{tabular}{|c|c|c|c|}
\hline $\begin{array}{l}\text { Variable Abdominal } \\
\text { Circumference }\end{array}$ & Pre exercise $(n=12)$ & $\begin{array}{l}\text { Post exercise } \\
\quad(n=12)\end{array}$ & significance* \\
\hline Endurance $(\mathrm{cm})$ & $105,79 \pm 7,38$ & $101,79 \pm 8,29$ & $0,004 *$ \\
\hline Resistance (cm) & $105,31 \pm 12,63$ & $104,38 \pm 12,40$ & 0,396 \\
\hline
\end{tabular}

* Paired $t$ test, the difference is significant if the significance value is $<0.05$

Table 5 LBM before and after Endurance and Resistance exercise.

\begin{tabular}{|c|c|c|c|}
\hline Variable LBM & Pre exercise $(n=12)$ & $\begin{array}{l}\text { Post exercise } \\
\qquad(\mathrm{n}=12)\end{array}$ & significance* \\
\hline Endurance $(\%)$ & $61.43 \pm 5.36$ & $82.17 \pm 7.54$ & $0,002 *$ \\
\hline Resistance (\%) & $58.27 \pm 9.96$ & $74.10 \pm 8.83$ & $0.000 *$ \\
\hline
\end{tabular}

*Test paired t test and Wilcoxon rank $\mathrm{t}$ test, the difference is significant if the significance value $<0.05$

The results of the paired t test (table 3) show that the BMI data before and after endurance training have a significant difference (significance 0.001). Body mass index before and after resistance training had no significant difference (significance 0.265 ).

The results of the paired $t$ test (table 4 ) showed that the data on the abdominal circumference before and after endurance exercise had a significant difference (significance 0.004). Pre- and post-resistance abdominal circumference had no significant difference (significance 0.396).

The results of the Wilcoxon rank t test (table 5) showed that the LBM data before and after endurance training had a significant difference (significance 0.002 ). Lean body mass before and after resistance training had a significant difference (significance 0.000 ).

\section{Static and Dynamic Balance Data Pre and Post Endurance}

Endurance group static balance data were analyzed using non-parametric Wilcoxon signed rank test because the data were not normally distributed. The endurance group dynamic balance data used parametric statistical tests because the data were normally distributed. The parametric test uses paired t-test. Data were taken before and after endurance training.

Table 6 Data for static and dynamic balance before and after Endurance exercise

\begin{tabular}{|c|c|c|c|c|}
\hline & variable & Pre exercise & Post exercise & significance* \\
\hline Endurance & $\begin{array}{c}\mathrm{KS}(\mathrm{s}) \\
\mathrm{KD} \text { (score) }\end{array}$ & $\begin{array}{c}2,21 \pm 0,80 \\
79,08 \pm 11,1\end{array}$ & $\begin{array}{c}3,93 \pm 1,44 \\
94,17 \pm 6,29\end{array}$ & $\begin{array}{l}0,019 * \\
0,000^{*}\end{array}$ \\
\hline
\end{tabular}

* Paired t test and Wilcoxon Signed rank test, the difference is significant if the significance value is $<0.05$

The results of the Wilcoxon signed rank test (table 6) showed that there was a significant difference between the pre- and post-endurance KS data (significance 0.019). The results of the paired t test (table 6) for preand post-endurance KD data (significance 0.000) have significant differences.

\section{Static and Dynamic Balance Data Pre and Post Resistance Exercise}

Static balance data of the resistance group were analyzed using non-parametric Wilcoxon signed rank test because the data were not normally distributed. The dynamic balance data of the resistance group used parametric statistical tests because the data were normally distributed. The parametric test uses paired t-test. Data were taken before and after resistance training. 
Table 7 Data for static and dynamic balance before and after resistance training

\begin{tabular}{|ccccc|}
\hline & variable & Pre exercise & Post exercise & significance* \\
\hline Resistance & $\mathrm{KS}(\mathrm{s})$ & $2,30 \pm 0,67$ & $4,05 \pm 1,66$ & $0,003^{*}$ \\
& $\mathrm{KD}(\mathrm{score})$ & $75,85 \pm 14,88$ & $95,38 \pm 6,29$ & $0,000^{*}$ \\
\hline
\end{tabular}

* test paired t test, test and Wilcoxon Signed rank test significant difference if the value of significance $<0.05$

The results of the Wilcoxon signed rank test (table 7) showed that the KS data before and after resistance training (significance 0.003 ) had a significant difference. The results of the paired t test (table 7) KD data before and after resistance training (significance 0.000) have a significant difference.

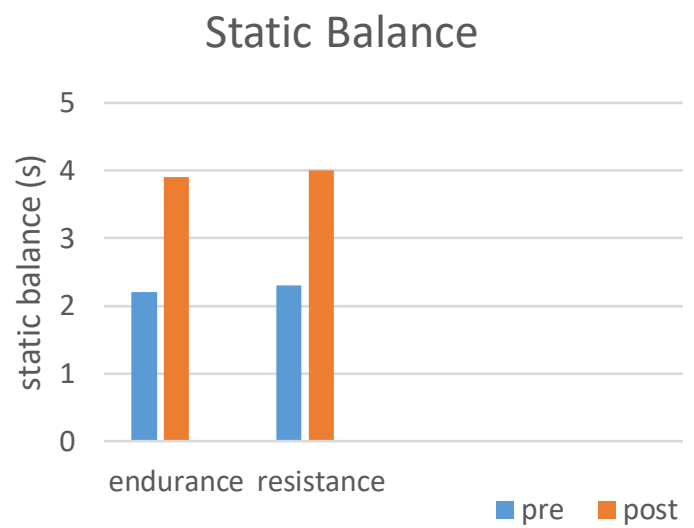

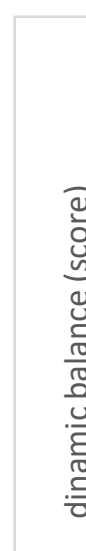

Dinamic Balance

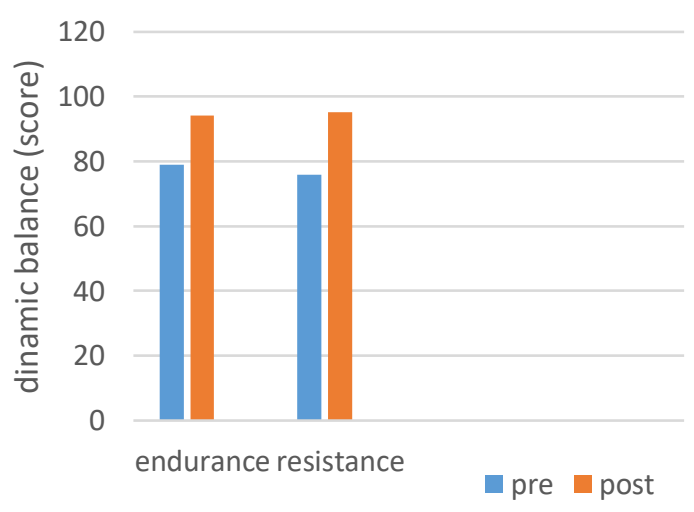

Intervention

Figure 2 Graph of static balance, dynamic pre and post endurance and resistance training for 8 weeks

\section{Data on Static and Dynamic Balance Differences between Endurance and Resistance Exercises}

Independent $t$ test was performed on both groups to determine the difference between static and dynamic balance before and after endurance training and resistance training.

Table 8 Differences in static and dynamic balance between endurance training and resistance

\begin{tabular}{|lllc|}
\hline \multicolumn{2}{c}{ training } & \\
\hline Variable & Endurance & Resistance & p-value \\
\hline KS post-pre (s) & $1,72 \pm 1,47$ & $1,76 \pm 1,49$ & 0,955 \\
KD post-pre (score) & $15,08 \pm 8,45$ & $19,54 \pm 11,62$ & 0,288 \\
\hline
\end{tabular}

*Test Independent t test, significant if $\mathrm{p}$ value $<0.05$

The results of the independent $t$ test (table 8 ) on the static balance between the 2 groups of endurance and resistance training performed after 8 weeks there was no significant difference with a $p$ value of 0.955 . There was also no significant difference between the 2 groups of endurance and resistance with a p value of 0.288 .

\section{DISCUSSION}

In this study, the initial characteristics of research subjects on the variables of age, body mass index (BMI), abdominal circumference, static balance and dynamic balance between the endurance and resistance groups were not significantly different with p-value $>0.05$.

The data of this study indicate that obese adolescents (average BMI above $30 \mathrm{~kg} / \mathrm{m} 2$ in both groups) have a risk of static and dynamic imbalances, this is indicated by standing stork test on all subjects (100\%) both in the endurance and resistance group had poor static balance and for dynamic balance with modified Bass balance test was in the $50 \%$ endurance group, while the $70 \%$ resistance group was classified as unbalanced (score $<80 \%$ ). Research subjects in both groups (100\%) had a large abdominal circumference (more than 90cm), LBM was less than normal (less than 76\%).

Abdominal circumference, large BMI, and LBM below normal were factors that contributed to the static and dynamic imbalance in both groups. The initial characteristics of the subjects of this study are in accordance 
with the study of Fenghua Sun et al (2015), which stated that obese children/adolescents had poor performance in static and dynamic postural control. The larger body size and body mass index, abnormal body fat distribution, and potential neuromuscular loss of obese children may contribute to their postural instability. Bataweel and Ibrahim (2020) also revealed the same fact, that the side effects of obesity in children are impaired postural balance and musculoskeletal flexibility disorders, center of mass (CoM) shift factor, decreased sensitivity of mechanoreceptors in the feet, and increased load on the lower extremities. suspected to be a factor responsible for balance disorders in obese children/adolescents.

This study aims to compare static and dynamic balance in obese adolescent boys after intervention of endurance and resistance exercise, according to the initial data of research subjects for the variables of BMI, age, abdominal circumference, LBM, static and dynamic balance are homogeneous, so that the two groups can be compared.

\section{Static and Dynamic Balance Pre and Post Endurance}

In this study, the post-intervention endurance group 3 times per week for 8 weeks could significantly improve static and dynamic balance (significance $<0.05$ ). In this endurance group, there was also a significant decrease in BMI and abdominal circumference, as well as a significant increase in LBM (significance <0.05).

The results of this study are supported by previous studies; Manjula et al (2018) which states that endurance training with Zumba fitness can increase trunk muscle strength, LBM, endurance, and balance. These changes will improve posture and increase skeletal muscle strength, as well as improve balance and coordination.

Kolayis and Arol (2020), also support this research. A study from Kolayis and Arol with zumba training on adolescent girls aged 15-17 years, BMI more than 24.9, zumba performed 3 times a week for 8 weeks showed a positive effect on body composition and improvements in functional mobility, as well as improvements in dynamic balance.

Bastug (2018), there is a significant difference between pre and post-intervention in body weight, BMI, flexibility, balance, and concentration in students who do endurance training with dancing (experimental group), compared to the control group who does not do dance exercises. This study was conducted on students with a mean age of 20.59 \pm 1.59 years, male and female, with an intervention of 30-70 minutes of exercise once a week for 14 weeks. Hugel et al (2007), also stated that physical exercise with dancing has the effect of strength, flexibility, endurance, balance and body coordination (Bastug, 2018).

This study showed that in the endurance group there was a significant decrease (significance $<0.05$ ) for BMI and abdominal circumference, as well as a significant increase in LBM after endurance training $3 \mathrm{x} /$ week for 8 weeks without calorie restriction. This statement is in accordance with the statement of Luettgen et al (2012), that Zumba burns an average of 369 calories or about $9.5 \mathrm{kcal}$ per minute. This Zumba exercise is done for 32-52 minutes in one workout. When practicing Zumba exercise, you will sweat and burn more calories. Zumba exercise three times a week in one month can lose $3 \mathrm{~kg}$ of body weight (Laela, 2016). Muriyati et al (2014) and Ljubojevic et al (2014) also state the same thing, that endurance training is effective for weight loss and fat loss if done regularly (Muriyati et al, 2014).

Fenghua Sun et al (2015), weight loss in obese adults can improve the stability of their posture. The study of Winter et al (1998), revealed a significant relationship between waist-abdominal circumference and the amount of foot or hand contact required by subjects to avoid falling while standing on one leg. The Mainenti MRM et al (2011) study stated that body weight, body mass index, abdominal circumference, fat percentage, and fat mass were positively and significantly correlated with the amount of contact required to avoid falling during a unilateral stance. Hannah et al, (2012) an increase in segmental mass, especially in the trunk in obesity, limits the range of motion of the knee joint during flexion and causes poor posture in obese people, this segmental mass in the trunk results in a forward shift of the Center of Mass (CoM), and limiting the Base of Support (BoS) which causes instability effects. Sizoo et al (2020), which stated that changes in LBM and fat-free mass will be associated with muscle mass. These studies can support the results of this study, where a significant decrease in BMI and abdominal circumference (tables 3 and 4) will have an effect on improving posture, improving CoM shift and improving foot contact to maintain balance. A significant increase in LBM (table 5) is associated with an increase in muscle mass which will contribute to increasing muscle strength. These parameters were not evaluated in this study (muscle mass, muscle strength, foot contact, posture and CoM shift), so further research is needed to support the results of this study.

\section{Static and Dynamic Balance before and after Resistance Training.}

In this study, the post-intervention resistance group 3 times per week for 8 weeks could improve static balance, dynamic balance, and significantly increase LBM (significance <0.05). Changes in BMI and abdominal circumference in the resistance group were not significant (significance $>0.05$ ). 
A systematic review from Sarabon and Kozinc (2020), showed that resistance training interventions can significantly improve balance in adults and the elderly. These findings have implications that resistance training can be used to improve muscle strength, as well as balance at the same time. Resistance exercises targeting mainly lower limb muscles with various types of load (body weight, elastic band, free weight, and resistance machines) have been shown to be effective for improving balance ability, the intervention should be long enough (4 weeks and more). In this systematic review the duration of training is between 6 to 14 weeks, 3 times a week. Studies were conducted on the elderly and adults, only one study was conducted on a population of healthy non-obese children (Šarabon and Kozinc, 2020).

Studies on resistance training in obese adolescents with the effects of static and dynamic balance are still very limited. So far, resistance training is not recommended for children/adolescents, because they are worried about the side effects of injury and require supervision. In this study, no side effects were reported during resistance training, so resistance training can be said to be safe for obese adolescents.

McGuigan et al (2009), this study examined overweight and obese adolescents in boys and girls with resistance training 3 times a week for 8 weeks, their research showed that there was a significant reduction in absolute body fat percent from 2.6\% ( $\mathrm{p}=0.003)$ and a significant increase in LBM 5.3\% $(\mathrm{p}=0.07)$. There were no significant changes in body weight, BMI, total fat mass, or bone mineral content. This study shows that a resistance training program produces significant changes in composition and strength.

Watts et al (2005), stated that BMI did not decrease significantly because this resistance exercise increased muscle mass. Resistance training is an effective exercise for inducing hypertrophy of specific muscle groups, increasing LBM, improving glycemic control, increasing basal metabolic rate and possibly losing fat as a consequence. This study was conducted on obese adolescent boys and girls, with resistance training 3 times a week for 8 weeks with an intensity of 50-70\% $1 \mathrm{RM}, 2$ sets of 12-15 repetitions, using the following techniques: leg press, bench press, military press, bicep curls, lat pull downs, tricep extensions and abdominal curls, without calorie restriction. This study showed no significant change in BMI, total body fat decreased by an average of $0.6 \%$ or about $700 \mathrm{~g}$ of fat tissue mass, which mostly came from the abdominal/total side as measured by DEXA and CT scan, subcutaneous fat did not change.

Van der Heijden et al, 2010; reported that after a 12-week resistance training program (2 sessions/week, session length of 1 hour in overweight and obese adolescents) there was an increase in body mass in adolescents aged 15 years, but $80 \%$ of this increase was due to an increase in muscle mass. This confirms previous studies showing that resistance training for 6 weeks in obese children can increase body muscle mass.

In this study, the resistance group experienced improvements in static and dynamic balance, but it was not followed by a significant decrease in BMI and abdominal circumference. An increase in LBM after intervention with resistance training 3 times a week for 8 weeks showed increased muscle mass, decreased body fat so that the BMI changes were not significant. Increased muscle mass will contribute to increasing muscle strength, this is the cause of increased static and dynamic balance in adolescents with obesity. This statement is in accordance with the study of Sizoo et al (2020), which states that changes in LBM and fat-free mass will be related to muscle mass. Thomas and Burns (2016), resistance training 3 times a week for 8 weeks can increase LBM and will increase muscle strength. Howard (2007), with an increase in muscle size, it will represent more muscle strength. Capodaglio et al (2012), showed that muscle strength plays an important role in dynamic conditions, normalizing body weight related to functional performance in obese patients. One of the prerequisites for balance control is the ability to produce muscles with sufficient muscle strength to maintain stability during movement.

In this study, the factors of changing body composition (increased muscle mass) and muscle strength that cause improvements in static and dynamic balance were not evaluated, so further research is needed to support the results of this study.

\section{Comparison of the Differences in Static and Dynamic Balance between Endurance and Resistance Training}

In this study, there was no significant difference static balance between 2 groups of endurance and resistance training after 8 weeks $(p>0.05)$. There was also no significant difference dynamic balance between 2 groups of endurance and resistance ( $p>0.05)$.

This study shows that both endurance and resistance training have a positive effect on improving static and dynamic balance in obese adolescents. In this study, no side effects were found in both groups, so it can be concluded that this type of exercise is safe for obese adolescents as long as exercise activities are carried out with appropriate procedures and under the supervision of a supervisor (especially for resistance training).

Willis et al (2012) compared resistance and endurance training. Endurance training reduces body weight and fat mass significantly more than resistance training. Changes in body fat percentage are driven by different mechanisms in which resistance training increases lean body mass (LBM) and endurance training decreases fat mass. This study demonstrated that endurance exercise significantly reduced visceral adipose tissue more than resistance exercise and tended to have similar results on changes in liver fat. 
In this study, resistance training with a shorter duration (average 20 - 35 minutes) resulted in BMI not decreasing significantly due to an increase in LBM, so that muscle mass would increase. This will affect the increase in muscle strength to improve static and dynamic balance. Resistance training involves type II fibers which have a greater capacity for hypertrophy, this is due to the hydrolysis of adenosine triphosphate (ATP) 2-3 times faster than type I fibers (Jacob et al, 2012). Muscle hypertrophy involving type II muscle cells through mechanisms of mechanical tension, muscle damage, and metabolic stress (Brad J, 2010).

In this study, endurance training with a duration of 45-60 minutes was able to reduce BMI and abdominal circumference better than resistance training, endurance training could also increase LBM. Endurance training causes a significant decrease in BMI, abdominal circumference, and a significant increase in LBM which will improve posture, thereby improving proprioception. An increase in LBM is related to an increase in muscle mass which will affect muscle strength to maintain balance during static and dynamic conditions. Endurance training involves recruiting exclusively type I motor units, increasing the size (cross-sectional area) of type I muscle fibers. Oxidative metabolism of type I muscle fibers will be increased by increasing the concentration of oxidative enzymes, mitochondrial size and number, and myoglobin content (Howard, 2007). ).

Increased abdominal circumference is associated with central obesity which is a component of the metabolic syndrome. Lack of physical activity, high calorie consumption, sedentary lifestyle, and high socioeconomic conditions are risk factors for metabolic syndrome in adolescents (Widjaja et al, 2020). Endurance training is able to reduce metabolic syndrome, this is because endurance exercise is able to induce antiinflammatory factors and anti-oxidative stress which have a neuroprotective effect on metabolic disorders (Jang et al, 2019). Improvement of this metabolic syndrome will affect several hormones, including an increase in insulin sensitivity and affect the testosterone hormone which has a function in glucose metabolism (Widjaja et al, 2020). This statement supports the results of this study, endurance exercise will increase fat oxidation as evidenced by a decrease in abdominal circumference. This significant decrease in abdominal circumference indicates an improvement in the metabolic syndrome, resulting in an increase in insulin sensitivity which will increase glucose uptake to increase muscle contraction, thereby increasing muscle strength as a necessary factor for static and dynamic balance in the endurance group. Resistance training can also improve metabolic syndrome because it improves glycemic control, but the results are better if you combine endurance and resistance training (Sorace et al, 2014). Willis et al (2012), showed that endurance training tends to increase metabolic syndrome scores significantly better than resistance training. This statement supports the results of this study, the endurance group reduced abdominal circumference better than the resistance group. In this study, the level of activity and calories that could affect the metabolic syndrome were not evaluated.

Exercise-induced adaptations are mainly seen in the cardiorespiratory, musculoskeletal, body composition and metabolic systems. Reduced anxiety and depressive symptoms are also an advantage of exercise. Skeletal muscles are the main target of sports training. Modification of skeletal muscle is very important to increase endurance and metabolic efficiency. It has been shown that regular exercise can reduce abdominal adiposity and improve weight control. Regular exercise has also been associated with increased psychological well-being (eg through reduced stress, anxiety, and depression). The mechanism behind this is not fully understood, but appears to be related to increased expression of neurotrophic factor in several brain areas. Increased expression of these factors is associated with better memory and cognition. Brain-derived neurotrophic factor (BDNF) can increase neuronal survival and differentiation, and exercise compliance has been shown to increase. The psychological impact has important implications for the prevention and management of obesity. Exercise has been shown to increase $\beta$-endorphins, this has been associated with psychological and physiological changes, including mood swings and euphoria (Vina et al, 2012). This increase in $\beta$-endorphins is associated with exercise addiction. Addiction occurs when there are adaptive changes in the brain that cause symptoms of tolerance, sensitization, and dependence, so that a person can increase his tolerance and dose of exercise. This addiction will change a behavior so as to increase motivation to exercise, this is influenced by 2 neurotransmitters dopaminergic and opioidergic (Leuenberger, 2006). This statement supports a fairly good compliance in the two intervention groups, both endurance and resistance, and research subjects can increase the intensity of exercise so that it has a positive effect on changes in body composition and muscle strength which will affect static and dynamic balance in obese adolescents.

Endurance and resistance training can improve static and dynamic balance in obese adolescents with different mechanism pathways. There are no studies that compare the effects of endurance training and resistance training on static and dynamic balance in obese adolescents. Further research is needed to prove other variables that can affect static and dynamic balance in adolescent boys with obesity, as well as the duration of the effect of endurance and resistance training on static and dynamic balance, because in this study, although there was a significant increase, in both the group for static balance with the standing stork test is still classified as poor.

Research Limitations

This study only took male subjects of puberty so that the results cannot be generalized. In this study only measuring BMI and abdominal circumference as a support for increasing static and dynamic balance, other supporting variables are still needed such as measurement of muscle mass, muscle strength and others. 


\section{CONCLUSION}

There was an increase in static and dynamic balance in obese adolescent boys after getting endurance training and resistance training 3 times per week for 8 weeks without calorie restriction. Endurance training and resistance training 3 times per week for 8 weeks, without calorie restriction, gave the same good effect (no differentiated) on increasing static and dynamic balance in obese adolescent boys.

Further research is needed to evaluate the effects of endurance and resistance training in a more diverse population so that the research results can be generalized, also needed to measure more diverse variables such as measurement of muscle mass and muscle strength to support the results of this study.

\section{REFERENCES}

Aucouturier, J and Thivel, D. 2015. Physical Activity Intervention In Overweight/Obese Children And Adolescents: Endurance And/Or Resistance Training?. European Childhoold Obesity Group. ebook.ecogobesity.eu

Bataweel and Ibrahim, 2020, Balance and musculoskeletal flexibility in children with obesity: a cross-sectional study, ANN Saudi med.

Bastug, 2018, Examination of Body Composition, Flexibility, Balance, and Concentration Related to Dance Exercise, Asian Journal of Education and Training

Benson ,Torode, Fiatarone Singh, 2006, A rationale and method for high-intensity progressive resistance training with children and adolescents, The School of Exercise and Sport Science, Faculty of Health Sciences, University of Sydney, East Street, Lidcombe, NSW, Sydney, Australia

Benson, Torode and Fiatarone Singh, 2008, The effect of high-intensity progressive resistance training on adiposity in children: a randomized controlled trial, The School of Medical Sciences, RMIT University, Melbourne, Australia

Brad J. Schoenfeld, 2010, The Mechanism of Muscle Hipertrophy and their application to Resistance training, Global Fitness Services Scarsdale, New York

Brian Masc, 2019, Standing Stork Test, sports coach, https://www.brianmac.co.uk/ 3 November 2019.

Castellani J, Fulco C, Kenefick R, Muza S, Pate R.2014. Chapter 8: Exercise Prescription for Healthy with Specail Considerations and Enviromental Consideration. ACSM's Guideline for Exercise Testing and Prescription $9^{\text {th }}$ Edition. Philadelphia. Lippincott Williams and Wilkins.

Connie W. Bales, Victoria H. Hawk, Esther O. Granville, Sarah B. Rose, Tamlyn

Shields, Lori Bateman1, Leslie Willis1, Lucy Piner1, Cris A. Slentz1, Joseph A. Houmard, Dianne Gallup1, Greg P. Samsa1, and William E. Kraus, 2012, Aerobic and Resistance Training Effects on Energy Intake: The STRRIDE AT/RT Study: Exercise Training Effects on Energy Intake, Associate director for Education/Evaluation, Geriatric Research, Education and Clinical Center, Fulton street Durham, NC

Capodaglio P \& V. Cimolin \& E. Tacchini \& C. Parisio \& M. Galli, 2012, Balance Control and Balance Recovery in Obesity, Orthopaedic Rehabilitation Unit and Clinical Lab for Gait Analysis and Posture, Ospedale San Giuseppe, Istituto Auxologico Italiano, Italy.

Damayanti Rusli Sjarif; Lanny Christine Gultom; Aryono Hendarto; Endang Dewi Lestari; I Gusti Lanang Sidiartha; Maria Mexitalia, 2014, Diagnosis, Tata Laksana dan Pencegahan Obesitas pada Anak dan Remaja, Rekomendasi Ikatan Dokter Anak Indonesia

Deborah Riebe, PHD, FACSM, ACSM-HF. 2014. General Principle of Exercise Prescription . ACSM's Guideline for Exercise Testing and Prescription $9^{\text {th }}$ Edition. Philadelphia. Lippincott Williams and Wilkins.p.162190

Elissa Jelalian and E. Whitney Evans, 2016, Behavioral intervention in the treatment of obesity in children and adolescents: implications for Mexico, Published by Oxford University Press on behalf of the International Life Sciences Institute

Emma Pomeroy, Alison Macintosh, Jonathan C.K. Wells, Tim J. Cole, and Jay T. Stock. 2018, Relationship between body mass, lean mass, fat mass, and limb bone cross-sectional geometry: Implications for estimating body mass and physique from the skeleton, School of NaturalSciences and Psychology, Liverpool JohnMoores University, Byrom Street, LiverpoolL3 3AF, UK

Fawker S and Amstrong N. 2012. Oxygen Uptake Kinetic Response to Exercise in Children. Sport Medicine; 33(9):651-669

Fenghua Sun, Li-Juan Wang and Lin Wang3, 2015, Effects of weight management program on postural stability and neuromuscular function among obese children: study protocol for a randomized controlled trial, School of Kinesiology, Shanghai University of Sport, Shanghai, China

FKM - UI. 2007. Aktivitas Fisik. Diunduh dari: http://lontar.ui.ac.id/ . 3 November 2019 
Gurevich-Panigrahi, 2009; Obesity: Pathophysiology and Clinical Management National Collaborative on Childhood Obesity Research.

Gunawan A, Hedison Polii, Damajanty, H. C. Pengemanan. 2015. Pengaruh Senam Zumba Terhadap Kebugaran Kardiorespirasi Pada Mahasiswa Fakultas Kedokteran Universitas Sam Ratulangi Angkatan 2014. Jurnal e-Biomedik (eBm), Volume 3, Nomor 1. Manado: Universitas Sam Ratulangi

Hannah C. Del Porto, Celia M. Pechak. Darla R. Smith, and Rebecca J. Reed- Jones, 2012 Biomechanical Effects of Obesity on Balance, Department of Kinesiology, College of Health Sciences, The University of Texas at El Paso, USA

Hao Meng Daniel P. O'Connor Beom-Chan Lee,Charles S. Layne Stacey L. Gorniak, 2015, Effects of adiposity on postural control and cognition, 3Texas Obesity Research Center, University of Houston, Houston

Helen N Sweeting, 2008, Gendered dimensions of obesity in childhood and adolescence, MRC Social and Public Health Sciences Unit, 4, Lilybank Gardens, Glasgow, G12 8RZ, UK

Hoffman D.J and Gallagher D., 2001.Obesity and Weight Control. In Gonzales (eds). Downey \& Darling's Physiological Basis of Rehabilitation Medicine. $3^{\text {rd }}$ Ed. USA, pp. 485-505

Howard G Knuttgen, 2007, Strength Training and Aerobic Exercise Comaparison and contrast, Department of Physical Medicine \& Rehabilitation, Harvard Medical School, Spaulding Rehabilitation Hospital, Boston, Massachusetts

Isreal Olabanji, 2019, Ischemic Heart Disease: Symptoms, Causes, Treatment and Prevention, https://www.healthsoothe.com/ischemic-heart-disease-symptoms-causes-treatment-andprevention/February4th,2020

Jacob M, Wilson, Jeremy P, Loenneke, Edward Jo, Gabriel J, Wilson, Michael C, Zourdos, and Jeong-Su Kim, 2012, The Effects of Endurance, strength, and power training on muscle fiber type Shifting, The University of Tampa, Florida; The University of Oklahoma, Norman, Oklahoma

Jang Y, Insu Kwon, Ludmila Cosio Lima, Christopher Wirth, Debra M. Vinci, and Youngil Lee, 2012, Endurance Exercise Prevents Metabolic Distress-induced Senescence in the Hippocampus, Molecular and Cellular Exercise Physiology Laboratory, Department of Movement Sciences and Health, Usha Kundu, MD College of Health, University of West Florida, Pensacola, FL.

Jenny Suing, 2007, Resistance Training for Obese Children and Adolescents, President's Council on Physical Fitness and Sports.

Julie Nantel, Marie-EveMathieu, and Franc, ois Prince, 2011, Physical Activity and Obesity: Biomechanical and Physiological Key Concepts, Department of Neurology and Neurological Sciences, Stanford University, Stanford USA.

Kolayis dan Arol, 2020, The effect of Zumba exercises on body composition, dynamic balance and functional fitness parameters in 15-17 years old women with high body mass index, Pedagogy of physical culture and sports.

Kwong Ming Fock and Joan Khoo, 2013, Diet and exercise in management of obesity and overweight, Departments of*Gastroenterology and $†$ Endocrinology, Changi General Hospital, Singapore

Laela nur, 2016, Hubungan senam Zumba dengan indeks massa tubuh.Universitas Muhammadiyah Surakarta

Laura Chaddock, Kirk I. Erickson,Ruchika Shaurya Prakash, Matt VanPatter Michelle W. Voss Matthew B. Pontifex Lauren B. Raine, Charles H. Hillman , Arthur F. Kramer, 2010, Basal Ganglia Volume Is Associated with Aerobic Fitness in Preadolescent Children, Department of Psychology, Beckman Institute for Advanced Science and Technology University of Illinois at Urbana-Champaign

Leuenberger Andrea, 2006, Endorphins, Exercise, and Addictions: A Review of Exercise Dependence, The Premier Journal for Undergraduate Publications in the Neurosciences.

Lifang Vikul, 2020, What is the purpose of stork balance stand test?, https://findanyanswer.com/what-is-thepurpose-of-stork-balance-stand-test/ 26/9/2021

Lifetime Fitness and Wellness, 2018, Muscular Atrophy and Hypertrophy, Effect exercise at muscular, Chapter 8: Muscle Strength and Endurance, Extended Learning Institute (ELI) at Northern Virginia CommunityCollege NOVA

Lifetime Fitness and Wellness, 2018, Effect of Exercise on Muscles, Sustained, repeated overload of a group of muscles leads to muscle hypertrophy and strengthening of that muscle group. Chapter 8: Muscle Strength and Endurance, Extended Learning Institute (ELI) at Northern Virginia CommunityCollege NOVA

Lucky Prasetiowati, Sasanthy Kusumaningtyas, Tirza Z Tamin, 2017, Effect of Body Mass Index on Postural Balance and Muscle Strength in Children Aged 8-10 years, Department of Medic Rehabilitation, Faculty of Medicine, University of Indonesia, Jakarta, Indonesia

Lukas Krondorf, 2018, Modified BASS Balance Test, Norwegian University of Science and Technology (NTNU) in Trondheim, Norway 
Madarina Julia, 2014, Obesitas pada Anak, IDAI Indonesian Pediatrics Society, Bagian Ilmu Kesehatan Anak, Fakultas Kedokteran UGM/ RS Sardjito Yogyakarta, http://www.idai.or.id/artikel/seputar-kesehatananak/obesitas-pada-anak/ 25 December 2018.

Mainenti MRM, E’rika de Carvalho Rodrigues, Juliana Fla'via de Oliveira, Arthur de Sa' Ferreira, Cristina Ma' rcia Dias, Andre' Lu1's dos Santos Silva, 2011, Adiposity and postural balance control: Correlations between bioelectrical impedance and stabilometric signals in elderly Brazilian women, Augusto Motta University Center (UNISUAM) - Postgraduate Program of Rehabilitation Sciences, Rio de Janeiro, Brazil.

Manjula Suri, Rekha Sharma Namita Saini, 2018, Physiological responses of Zumba: an Overview understanding the popular fitness trend, Department of Physiology and Promotive Health, University of Delhi, Institute of Home Economics, India

Marni N. Silverman and Patricia A. Deuster,2014, Biological mechanisms underlying the role of physical fitness in health and resilience, Consortium for Health and Military Performance, Department of Military and Emergency Medicine, Uniformed Services University of the Health Sciences, Bethesda, MD 20814, USA

Mark A. W. Andrews, 2003, How does exercise make your muscles stronger?, Associate professor of physiology and director of the Independent Study program at the Lake Erie College of Osteopathic Medicine, provides the following explanation

Mark A. Tresierras, MA, and Gary J. Balady, MD, 2009, Resistance Training in the Treatmentof Diabetes and Obesity, Mechanisms and Outcomes, Boston UniversitySchool of Medicine, and Section of Cardiology, Boston MedicalCenter, Boston, Massachusetts

Mary S. Ahn, MD Boris Birmaher, MD. Lisa Cullins, MD. Timothy Dugan, MD. Gregory K. Fritz, MD. Mary Margaret Gleason, MD. Pamela E. Hoffman, MD. Melvin D. Oatis, MD. Scott M. Palyo, MD. Marian A. Swope, MD. John T. Walkup, MD, 2016, Obesity In Children And Teens, American Academy of Child and Adolescent Psychiatry.

Marwa S.M. Saleha, Walaa Abd El-Hakiem Abd El-Nabie, 2017, Influence of obesity on proprioception of knee and ankle joints in obese prepubertal children, Departments of Physical Therapy Basic Science, Physical Therapy for Paediatrics, Faculty of Physical Therapy, Cairo University, Giza, Egypt

M. Cauderay, F. Cachat, 2015, Analysis of exercise training for treating obesity in children and adolescents: a review of recent, Department of Pediatrics, Division of Pediatric Nephrology, Bern, Switzerland.

Mc Guigan, Tatasciore, Newton, Simone Pettigre, 2009, Eight weeks of Resistance training can significantly alter body composition in children who are overweight or obese, National Strength and Conditioning Association.

McManus dan Mellecker, 2012, Physical activity and obese children, Institute of Human Performance, University of Hong Kong, China

McWhorter J.W, Wallman,H.W, and Alpert, P.T, 2003. The Obese Child: Motivation as Tool for Exercise. Journal of Pediatric Health Care. Las Vegas.

Michael Freemark, 2010, Pediatric Obesity Etiology, Pathogenesis, and Treatment, Division of Pediatric Endocrinology and Diabetes Duke University.

Michelle C and Asker E, 2007, Endurance Training and Obesity: Effect on Substrate Metabolism and Insulin Sensitivity. Human Performance Laboratory, School of Sport and Exercise Sciences, The University of Birmingham, Edgbaston, United Kingdom

Middlesworth, 2012, The Definition and Causes of Musculoskeletal Disorders, https://ergoplus.com/musculoskeletal-disorders-msd/February4th 2020

Muryati Patima, A. Suswan, 2014, Latihan Aerobik Terhadap Perubahan Indeks Massa Tubuh (IMT) pada Individu Overweight dan Obesitas, Stikes Panrita Husada Bulukumba

Mojgan Banihashemi Emamghis, Gholamreza Sharif, Iman Zakavi, Alireza Babaei, Mazreno, 2015, Comparative Study of the Effect of Aerobic and Resistance Exercise on Static and Dynamic Balance in Elderly Males, Shahid Sadoughi University of Medical Sciences, Yazd, Iran

Neslihan Koyuncuoğlu Güngör, 2014, Overweight and Obesity in Children and Adolescents, Louisiana State University Health Sciences Center-Shreveport, Department of Pediatric Endocrinology, Shreveport, LA, USA

Ronald J. Sigal, MD, MPH; Angela S. Alberga, PhD; Gary S. Goldfield, PhD; Denis Prud'homme,MD, MSc; Stasia Hadjiyannakis, MD; Réjeanne Gougeon, PhD; Penny Phillips, MA; Heather Tulloch, PhD; Janine Malcolm, MD; Steve Doucette, MSc; George A.Wells, PhD; Jinhui Ma, PhD; Glen P. Kenny, PhD, 2014, Effects of Aerobic Training, Resistance Training, or Both on Percentage Body Fat and Cardiometabolic Risk Markers in Obese Adolescents The Healthy Eating Aerobic and Resistance Training in Youth Randomized Clinical Trial, Faculties of Medicine and Kinesiology, University of Calgary, Canada.

Ramos-Campo, Luis Andreu Caravaca, Alejandro Martínez-Rodríguez and Jacobo Ángel Rubio-Arias, 2021, Effects of Resistance Circuit-Based Training on Body Composition, Strength and Cardiorespiratory Fitness: A Systematic Review and Meta-Analysis, MDPI stays neutral with regard to jurisdictional claims in published maps and institutional affiliation. 
Salvadeg, Lazzer S, Busti C, Galli R, Agosti F, and Lafortuna C. 2010. Gas Exchange Kinetics In Obese Adolescents. Inferences On Exercise Tolerance And Prescription. Am J Physiol Regul Integr Comp Physiol;299: 1298e305.

Šarabon and Žiga Kozinc, 2020, Effects of Resistance Exercise on Balance Ability: Systematic Review and MetaAnalysis of Randomized Controlled Trials, www.mdpi.com/journal/life.

Sizoo D, Loek J. M. de Heide, Marloes Emous, Tim van Zutphen, Gerjan Navis \& André P. van Beek , 2020, Measuring Muscle Mass and Strength in Obesity: a Review of Various Methods, Springer Obesity Surgery.

Sjarif D, Nasar S, Devaera Y, dan Tanjung C. 2011. Asuhan Nutrisi Pediatrik. Ikatan Dokter Anak Indonesia.

Sjarif D, Gultom L, Hendarto A, Lestari E, Sidiartha I, danMexitalia M. 2014. Diagnosis, Tatalaksana dan Pencegahan Obesitas pada Anak dan Remaja. Ikatan Dokter Anak Indonesia.

Steinberg Nilli, Alon Eliakim, Reuven Kohen, Nemet, 2013 The effect of a weight management program on postural balance in obese children, Zinman College of Physical Education and Sport SciencesWingate InstituteNetanyaIsrael

Steinberg Nilli, Nemet, Michal Pantanowitz and Alon Eliakim, 2018, Gait Pattern, Impact to the Skeleton and Postural Balance in Overweight and Obese Children: A Review, Wingate College of Physical Education and Sports Sciences, Wingate Institute, Child Health and Sport Center, Pediatric Department, Meir Medical Center, Sackler School of Medicine, Tel Aviv University Israel

Simone Laraa,*, Susane Graupa, Rodrigo de Souza Balka, Lilian Pinto Teixeiraa, Ariane Dias Fariasa, Giselle Baioco Alvesa, Verônica Benachio Leiriaa, 2017, Association Between Postural Balance and Atropometric Indexes in Elementary Schoolchildren, Universidade Federal do Pampa, Uruguaiana, RS, Brazil

SoJung Lee,Fida Bacha,Tamara Hannon,Jennifer L. Kuk,Chris Boesch,and Silva Arslanian, 2012, Effects of Aerobic Versus Resistance Exercise WithoutCaloric Restriction on Abdominal Fat, IntrahepaticLipid, and Insulin Sensitivity in Obese Adolescent BoysA Randomized, Controlled Trial, Division of Weight Management \& Wellness, Children's Hospitalof Pittsburgh of UPMC, University of Pittsburgh School of Medicine,Pittsburgh, Pennsylvania.

Sorace Paul, Peter Ronai, and James R. Churilla, 2014, Resistance training and metabolic syndrome, American College of Sports Medicine.

Sukma A.T. 2015. Efek Zumba Terhadap Penurunan Tebal Lemak Tubuh Bawah Kulit dan Berat Badan Member DF Fitness dan Aerobic. Jurnal e-Biomedik (eBm). Yogyakarta: Universitas Negeri Yogyakarta

Thomas Michael and Burns Steve, 2016, Increasing Lean Mass and Strength: A Comparison of High Frequency Strength Training to Lower Frequency Strength Training, Department of Kinesiology, University of Central Missouri, Warrensburg, MO, USA.

Utomo GT, dkk, 2012 Latihan Senam AerobikUntuk Menurunkan Berat Badan,Lemak, Dan Kolesterol, Jurusan Ilmu Keolahragaan, Fakultas Ilmu Keolahragaan, Universitas Negeri Semarang, Indonesia.

Vina J, F Sanchis-Gomar, V Martinez-Bello and MC Gomez-Cabrera, 2012, Exercise acts as a drug the pharmacological benefits of exercise, British Journal of Pharmacology.

Volker Dietz, 2002, Proprioception and Locomotor disorders, ParaCare, Institute for Rehabilitation and Research, University Hospital Balgrist, Forchstrasse 340, CH 8008, Zurich, Switzerland

Watts, Timothy W. Jones, Elizabeth A. Davis and Daniel Green, 2005, Exercise Training in Obese Children and Adolescents, https://www.researchgate.net/publication/7845629

WHO, 2014, Obesity, https://www.who.int/topics/obesity/en/ 22 April2019

WHO, 2016, Childhood overweight and obesity, https://www.who.int /dietphysicalactivity/childhood/en/April21th 2019

Widjaja Nur Aisiyah, Rendi Aji Prihaningtyas, Meta Herdiana Hanindita, Roedi Irawan, 2020, Diet dan Sindrom Metabolik pada Remaja Obesitas, IAGIKMI \& Universitas Airlangga

Winter DA, Patla AE, Prince F, Ishac M, Gielo-Perczak K, 1998, Stiffness control of balance in quiet standing.J Neurophysiol. 1998 Sep; 80(3):1211-21.

William S. Garver•Sara B. Newman•Diana M. Gonzales-Pacheco•Joseph J. Castillo•David Jelinek•Randall A. Heidenreich-Robert A. Orlando, 2013, The genetics of childhood obesity and interaction with dietarymacronutrients, Springer-Verlag Berlin Heidelber.

WilliamJ.Kraemer.Michael R.Deschenes'andStevenJ. Flecx, 1988, Physiological Adaptations to Resistance Exercise Implications for Athletic Conditioning, Department of Sport, Leisure and Exercise Sciences and Department of Physiology and Neurobiology, The University of Connecticut, Storrs, Connecticut, USA

Willis, Cris A. Slentz, Lori A. Bateman, A. Tamlyn Shields, Lucy W. Piner, Connie W. Bales, Joseph A. Houmard and William E. Kraus, 2012, Effects of Aerobic and/or Resistance Training on Body Mass and Fat Mass in Overweight or Obese Adults, American Physiological Society, NHLBI.

Wolfram Doehner, Guelistan Turhan, Francisco Leyva, Mathias Rauchhaus, Anja Sandek, Ewa A Jankowska, Stephan von Haehling and Stefan D Anker, 2015, Skeletal muscle weakness is related to insulin resistance in patients with chronic heart failure, Center for Stroke Research Berlin (CSB), Charite Universitätsmedizin Berlin, Berlin, Germany. 